\title{
Exclusive Breast Feeding and Its Associated Factors Among Mothers of $<12$ Months Old Child in Harar Town, Eastern Ethiopia: A Cross-Sectional Study
}

This article was published in the following Dove Press journal:

Pediatric Health, Medicine and Therapeutics

\author{
Teshale Mulatu Dibisa $\mathbb{D}$ \\ Yitagesu Sintayehu (D) \\ Department of Midwifery, Haramaya \\ University, College of Health and Medical \\ Sciences, School of Nursing and \\ Midwifery, Harar, Ethiopia
}

Background: Exclusive breast-feeding is the practice of feeding breast milk during the first 6 months and no other liquids and solid foods except medications. Despite its demonstrated benefits, exclusive breast-feeding practice in many countries including Ethiopia is lower than the international recommendation. However, studies about exclusive breast-feeding in the study area are limited. Therefore, this study aimed to fill this gap.

Methods and Materials: Community-based cross-sectional study was employed. A cluster sampling method was used to select 577 women who had a child aged $<12$ months. Data were collected using a pretested interviewer-administered questionnaire. Epi-Data version 3.1 and SPSS version 21 were used for data entry and analysis. Bivariate and multivariate logistic regressions were used to analyze the association between the dependent and independent variables.

Results: A total of 577 study participants have participated in the study which gives $97.8 \%$ response. Exclusive breast-feeding practice among the mothers was $45.8 \%$. Women in the age group of 26-40 were 2 times more likely to breast-feed than women in the age group of $18-25$ at $(\mathrm{AOR}=1.980[95 \% \mathrm{CI}=1.098,3.570])$. Women who have information about exclusive breast-feeding were two times more likely to breast feed than those who have no information at $(\mathrm{AOR}=1.952[95 \% \mathrm{CI}=1.130,3.373])$. Those women who initiated breastfeeding early were 12 times more likely to breastfeed than those women who did not initiate early at $(\mathrm{AOR}=12.336[95 \% \mathrm{CI}=1.331,14.316])$

Conclusion: The overall exclusive breast-feeding practice among the women was found to be less. Age, information on breast-feeding and early initiation of breast-feeding were found as important predictors of exclusive breast-feeding. Improving access to information on recommended infant feeding is vital, and encouraging exclusive breast-feeding among mothers through proper counseling and mother-friendly work environment is advisable.

Keywords: breast-feeding, exclusive breast-feeding, practice, Harar

\section{Background}

Exclusive breast-feeding (EBF) is the practice of feeding breast milk (including expressed breast milk) during the first 6 months and no other liquids and solid foods, except medications. ${ }^{1}$ Exclusive breastfeeding offers both nutrition and protection from diseases and when given for 6 months will save 1.3 million infants worldwide annually. According to the WHO report, $37 \%$ of infants aged less 6 months are breastfed exclusively worldwide. In the case of Africa, only fewer than $1 / 3$ of under 6 months of infants breastfed exclusively. ${ }^{2,3}$
Correspondence: Yitagesu Sintayehu $\mathrm{Tel}+251913276896$

Email Yitagesu.sintayehu@gmail.com 
Internationally, there has been advancement in improving child survival. However, many declarations were passed to decrease child death by two thirds by 2015 from the level recorded in 1990; in the last two decades, the under-five mortality was diminished by half in 2013, from 12.7 to 6.3 million. Sub-Saharan Africa (SSA), where the under-five deaths are 15 times higher than the deaths in an average high-income country, continues to bear the greatest problem. Ethiopia is among the developing countries where the highest infant mortality rate (59/ 1000 live birth) occurs. ${ }^{4}$

Poor infant feeding has negative consequences on the health and nutritional status of children; it affects the physical and cognitive development of the children. Breastfeeding is a vital element of a child's nutritional status that determines his/her growth and development. ${ }^{5}$

Globally, malnutrition contributes $60 \%$ of the 10.9 million annual deaths among under-five children. Greater than two-thirds of these deaths are related to inappropriate feeding practices that occur during the first year of life. Inadequate breastfeeding accounts for $45 \%$ of deaths related to neonatal infections, $30 \%$ of deaths related to diarrhea, and $18 \%$ of deaths related to acute respiratory diseases among under-five children. ${ }^{6}$

According to the Ethiopian Demographic Health Survey (EDHS) 2016, only 58\% of infants were exclusively breastfed during the survey, which showed slight improvement, but still lower than the WHO recommendation. In contrast to $\mathrm{WHO}$ recommendation, the survey report showed that $17 \%$ of infants aged $0-5$ months consume plain water, $5 \%$ consume no milk liquids or other milk and $11 \%$ were introduced complementary foods in addition to breast milk. ${ }^{7}$

Several strategies have been identified by UNICEF and WHO to promote EBF practices. These include starting breast-feeding within 1 hour of births, EBF for first 6 months of infant life, and appropriate weaning after 6 months and complementary foods while continuing to breast feeding for 2 years. ${ }^{4}$

The Ministry of Health of Ethiopia has tried to enhance optimal breastfeeding practice by developing training manuals and implementation guidelines on breastfeeding. These have been incorporated into the primary health care system in line with the health extension program but breastfeeding practice remains far from the global recommendation. ${ }^{8}$ To achieve the Sustainable Development Goal in reducing child mortality, infant breastfeeding has been identified as one of the major intervention areas both globally and nationally.
Therefore, the aim of this study was to assess the magnitude of exclusive breast-feeding practice and its associated factors among women who had a child aged $<12$ months, which is mandatory to implement interventions that speed up the government efforts and decrease the rate and burden of infant morbidity.

\section{Methods and Materials}

\section{Study Setting and Period}

The study was conducted in Harar town. It is the capital of East Hararghe and the Harari Regional State. With a total area of 343.2 square kilometers (Urban $=19.5 \mathrm{Sq} \mathrm{Km}$ and Rural $=323.7 \mathrm{Sq} \mathrm{Km}$ ), Harar is located in the Eastern part of Ethiopia, $516 \mathrm{~km}$ from Addis Ababa, and at an elevation of 1885 meters. The total population of the town is 245,000 . Of these, $52.2 \%$ are female and $47.8 \%$ are male. The crude birth rate and general fertility rate for the year 2013 were 20.3 and 64 births per 1000, respectively. In 2013, the Total Fertility Rate (TFR) was 1.9 births per woman of reproductive age. ${ }^{9,10}$ The study was conducted from July 1-30/2019.

\section{Study Design and Population}

A community-based retrospective cross-sectional study was conducted among the mothers residing in the selected kebeles of the study area for more than 6 months, and who had a child $<12$ months of age. The mothers who could not communicate due to illness and who were not available in home during the data collection period after three visits were excluded from the study.

\section{Sample Size Determination and Sampling Procedure}

Single population proportion formula, $\mathrm{n}=(\mathrm{Z} \alpha / 2)^{2} \mathrm{pq} / \mathrm{d}^{2}$ was used with the proportion (58\%) which was taken from EDHS $2016 .^{7}$ A confidence level of $95 \%$ and a $5 \%$ degree of precision were used. By considering the 1.5 design effect and 5\% non-response rate, the final sample size was 590 .

A cluster sampling technique was used and five kebeles (the smallest administrative units) were selected by the lottery method. Proportional allocation for each kebele was used to give equal chance. A systematic random sampling technique was used to select study participants among the households until the desired sample size was achieved.

\section{Data Collection Tools, Procedure and Quality Control}

An interview-based a structured questionnaire was used to collect data. It was prepared in English, then translated 
into Amharic, then translated back into English to maintain the reliability, and finally administered in Amharic. Three health extension workers were recruited for the data collection. Mothers from selected households who had a child aged $<12$ months during the survey were interviewed. If more than one mother/women who had an infant aged $<12$ months were in the selected household, only one of them was interviewed and the data were collected regarding the EBF practices during the child age from 0 to 6 months. During the interview, when eligible participant was not present in the household visit, we visited three times and then excluded those were not available within those three visits. The interview was taken around 45 minutes for each participant.

To control the data quality, three-day training was given for the supervisor and the data collectors. The tools were pre-tested and modifications were made to fit our set up based on the pretest result. The collected data were checked on a daily basis for completeness and cleaned manually and double data entry was performed to check clarity.

\section{Operational Definitions}

\section{Exclusive Breastfeeding}

Feeding only breast milk for at least 6 months except for ORS, drops, syrups (vitamins, medicine, and minerals) do not allow anything else in the past $24 \mathrm{hrs}$ before the survey for the babies who were less than or equal to 6 months.

\section{Early Initiation of Breast-Feeding}

Initiating feeding breast milk within 1 hour after delivery.

\section{Complementary Feeding}

Introducing any food or liquid, including non-human and solid or semi-solid foods to the baby after 6 months.

\section{Knowledge Score on EBF}

An average of responses on knowledge variables will be done by computing variables. Mothers who scored less than the mean score were labeled to have poor knowledge and those who scored above the mean score as having good knowledge.

\section{Data Processing and Analysis}

The data were entered into the computer by using EpiData Version 3.0.2. Data analysis was done by using Statistical Package for social science (SPSS) software Version 21. Frequencies of variables were generated; tabulation and percentages were used to illustrate study findings. Pearson correlation test was done to see the relationship between variables. The association between the outcome variables (ie, EBF practice) and independent variables was analyzed using a logistic regression model. Covariates with a P-value $<0.2$ were retained and entered into the multivariable logistic regression analysis using a forward selection and backward elimination approach. Hosmer and Lemeshow's goodness-of-fit test was used to assess whether the necessary assumptions were fulfilled. Adjusted odds ratio (AOR) with $95 \%$ confidence intervals (CI) using a P-value $<0.05$ was considered as statistically significant association with the outcome variable.

\section{Ethical Consideration}

Ethical clearance for the study was obtained from the IRB of Saint-Paul Hospital Millennium Medical College (SPHMMC). Formal letters were written to all concerned authorities and permission was secured at all levels. Informed voluntary, written and signed consent was obtained from each respondent after explaining the purpose and procedure of the study. All the basic principles of human research ethics (respect of persons, beneficence, voluntary participation, confidentiality and justice) were respected.

\section{Results}

\section{Socio-Demographic Characteristics of Respondents}

A total of 577 study participants have participated in the study, which gives a $97.8 \%$ response rate. The study participants were with a mean age of 32.6 years and $9.5 \pm$ SD (Table 1).

\section{Breast-feeding practice of study participants}

The study finding showed that only $45.8 \%$ of the mothers exclusively breast-fed their infant. Many of the study participants $(69.3 \%)$ initiated breastfeeding immediately after delivery. Regarding the frequency of breast-feeding, $40.1 \%$ of the mothers fed $2-3$ times/day, and $37.2 \% 4-7$ times/day. In the last 24 hours (recall), $64.6 \%$ of them had given their baby extra liquid/solid food. The majority of the study participants provide animal milk $(81.5 \%)$ as additional liquid and porridge (72.6\%) as semisolid food. When asked their reason for giving additional liquids/ semi-solid foods, many of the mothers answered that their baby got hungry $(78 \%)$, that breast milk alone was not enough (74.8\%), and that they did not produce enough breast milk $(69.2 \%)$. 
Table I Sociodemographic Characteristics of Study Participants Towards Exclusive Breast-Feeding, Harar Town, Harari Regional State, Eastern Ethiopia $(n=577)$

\begin{tabular}{|c|c|c|}
\hline Variables & Frequency (n) & Percentage (\%) \\
\hline \multicolumn{3}{|l|}{ Age } \\
\hline $18-25$ & 256 & 44.4 \\
\hline $26-40$ & 321 & 55.6 \\
\hline \multicolumn{3}{|l|}{ Marital status } \\
\hline Married & 532 & 92.2 \\
\hline Divorced & 37 & 6.4 \\
\hline Others & 8 & 1.4 \\
\hline \multicolumn{3}{|l|}{ Religion } \\
\hline Muslim & 413 & 71.6 \\
\hline Orthodox & 118 & 20.5 \\
\hline Protestant & 41 & 7.1 \\
\hline Others & 5 & 0.86 \\
\hline \multicolumn{3}{|l|}{ Ethnicity } \\
\hline Oromo & 208 & 36 \\
\hline Amhara & 64 & II.I \\
\hline Harari & 230 & 39.9 \\
\hline Somali & 49 & 8.5 \\
\hline Others & 26 & 4.5 \\
\hline \multicolumn{3}{|l|}{ Mother education } \\
\hline Unable to read and write & 91 & 15.8 \\
\hline Primary school & 234 & 40.6 \\
\hline Secondary school \& above & 205 & 35.5 \\
\hline College or university & 47 & 8.1 \\
\hline \multicolumn{3}{|l|}{ Mother occupation } \\
\hline Housewife & 319 & 55.3 \\
\hline Government employee & 121 & 21 \\
\hline Private employee & 56 & 9.7 \\
\hline Merchant & 69 & 12 \\
\hline Others & 12 & 2 \\
\hline \multicolumn{3}{|l|}{ Average monthly income } \\
\hline $300-2500$ & 136 & 23.6 \\
\hline $250 \mathrm{I}-5000$ & 236 & 40.9 \\
\hline$>5000$ & 205 & 35.5 \\
\hline
\end{tabular}

\section{Knowledge of study participants about exclusive breast-feeding}

The study showed that the overall knowledge of study participants was $68.46 \%$. Many of the study participants (444 (76.9\%)) had heard about exclusive breast-feeding and the most cited source of information was health facility 406 (70.4\%), media 191 (33.1\%), Family/friends/ relatives $(22.4 \%)$ and from other sources $(0.7 \%)$.

Regarding the knowledge about exclusive breastfeeding, almost all the study participants (97.6\%) knew that breastmilk should be given immediately after birth for the baby and $86 \%$ of the study participants knew that the first milk/colostrum should be given for the baby. Many of the study participants $(74.8 \%)$ believed that breast milk alone is adequate for the baby for the first 6 months.

Concerning complementary feeding, $31.7 \%$ of the study participants believed that additional fluids or semisolid should be introduced to the baby and the majority of them responded that complementary feeding should start at 6 months (73.8\%) and only 3.2\% stated that complementary feeding should start at 7 months and above.

\section{Obstetrics and Infant Conditions of Study Participants}

The obstetric and infant conditions of the study participants assessed in the study were indicated here below as reported by the mothers (Table 2).

\section{Factors Associated with Exclusive Breast-Feeding}

Age, number of pregnancies, breast-feeding information, and early initiation of breast-feeding were found as important predictors of exclusive breast-feeding in the bivariate analysis. After adjusting for other variables, only three variables (Age, information on breast feeding and early initiation of breast-feeding) remained significant in the multivariate logistic regression (Table 3).

\section{Discussion}

This study finding showed that the overall practice of exclusive breast-feeding among the mothers was $45.8 \%$. This is in line with other study findings in Cameroon $(45.2 \%)^{11}$ and Nepal $(45 \%){ }^{12}$ It is also similar to other study findings which were conducted at Mecha district, North West Ethiopia (47.13\%). ${ }^{13}$ Bahirdar city $(50.3 \%)$ and (49.1\%)., ${ }^{14,15}$ and Mota town, East Gojjam zone (50.1\%). ${ }^{16}$

The prevalence of EBF in this study is lower than the ones found by studies conducted in Debre Berhan, Central Ethiopia (68.6\%). ${ }^{17}$ Debre Markos, Northwest Ethiopia (60.8\%). ${ }^{18}$ Hossana town (70.5\%), and Offa district (78.0\%). ${ }^{19-21}$

It was also lower than the prevalence reported from Dubti town (81.1\%), Afar Regional State ${ }^{22}$ and the national level prevalence of $58 \%$ reported by Ethiopian Demographic and 
Table 2 Obstetrics and Infant Conditions of Study Participants Towards Exclusive Breast-Feeding, Harar Town, Harari Regional State, Eastern Ethiopia $(n=577)$

\begin{tabular}{|c|c|c|}
\hline Variable & Frequency (n) & Percentage (\%) \\
\hline \multicolumn{3}{|c|}{ Number of children in family } \\
\hline I & 275 & 47. 7 \\
\hline $2-3$ & 185 & 32 \\
\hline 4 above & 117 & 20.3 \\
\hline \multicolumn{3}{|c|}{ Antenatal care follow-up } \\
\hline Yes & 544 & 94.3 \\
\hline No & 33 & 5.7 \\
\hline \multicolumn{3}{|c|}{ Antenatal care visits } \\
\hline I visit & 26 & 4.8 \\
\hline 2 visits & 105 & 19.3 \\
\hline 3 visits & 194 & 35.6 \\
\hline 4 visits and above & 219 & 40. 3 \\
\hline \multicolumn{3}{|l|}{ Place of delivery } \\
\hline Home & 34 & 5. 9 \\
\hline Health facility & 543 & 94.1 \\
\hline \multicolumn{3}{|l|}{ Mode of delivery } \\
\hline Vaginal delivery & 467 & 86 \\
\hline Cesarean section & 76 & 14 \\
\hline \multicolumn{3}{|l|}{ Sex of the child } \\
\hline Male & 325 & 56.3 \\
\hline Female & 252 & 43.7 \\
\hline \multicolumn{3}{|l|}{ Postnatal care } \\
\hline Yes & 543 & 94. 1 \\
\hline No & 34 & 5.9 \\
\hline \multicolumn{3}{|l|}{ Baby illness/sick } \\
\hline Yes & 128 & 22. 2 \\
\hline No & 449 & 77.8 \\
\hline \multicolumn{3}{|l|}{ Disease condition } \\
\hline Vomiting & 90 & 15.9 \\
\hline Diarrhea & 81 & 14 \\
\hline Fever & 83 & 14.3 \\
\hline Common cold & 87 & I5. I \\
\hline Cough & 71 & 12.3 \\
\hline Skin allergy & 69 & 11.9 \\
\hline Others & 35 & 6.03 \\
\hline
\end{tabular}

Health Survey (EDHS) in $2016 .^{7}$ This difference might be due to the variation in culture and socio-economic characteristics of the study participants and the presence of NGOs in those study areas working on infant and young child feeding.
The magnitude of EBF in our study is slightly higher than the ones found by studies conducted in Nigeria $(31 \%),{ }^{23}$ Dabat district $(30.7 \%)$, northwest Ethiopia, ${ }^{24}$ Addis Ababa (central Ethiopia) (29.3\%), ${ }^{25}$ Tanzania $(24.1 \%),{ }^{26}$ and Bangladesh (35.9\%). ${ }^{27}$ This can be justified with a variation of study setting and study population.

The study revealed that $68.46 \%$ of the mothers had good knowledge of exclusive breastfeeding. The finding is consistent with the study which was conducted at Dabat, Northwest Ethiopia, which reported that $69.8 \%$ of the mothers had good knowledge about EBF. ${ }^{28}$

This finding is higher than that of the study conducted in Nigeria, which reported that $31 \%$ of the mothers had adequate knowledge of exclusive breastfeeding. ${ }^{23}$ In Bahirdar, $28.7 \%$ of the mothers had knowledge of infant and young child feeding recommendation ${ }^{29}$ and Mizan Aman town, Southwestern Ethiopia, where $34.7 \%$ of the women were knowledgeable about EBF. ${ }^{30}$ This difference might be due to the difference in the study settings and awareness level of the community.

The current study showed that maternal age, information on breast-feeding, and early initiation of breast-feeding were associated with the practice of exclusive breast-feeding. This finding is consistent with other study findings. ${ }^{17,19-22,26}$

The study showed that the women in the age group of 26-40 were about 2 times more likely to exclusive breastfeed their infants than those in the age group of 18-25 at $(\mathrm{AOR}=1.98[95 \% \mathrm{CI}=1.10,3.57])$. This is in line with the results reported from Debre Berhan ${ }^{17}$ and Tanzania ${ }^{26}$ as an important predictor of EBF.

The women who had information about EBF were about 2 times more likely to exclusive breast-feed their infants (AOR $=1.95[95 \% \mathrm{CI}=1.13,3.37])$. The finding is in line with other study findings in Offa district, Southern Ethiopia ${ }^{21}$ and Halaba special woreda, SNNP, Ethiopia, ${ }^{19}$ and have a significant association with exclusive breastfeeding.

The women who initiated breastfeeding early were 12 times more likely to exclusive breast-feed their infants (AOR $=12.33[95 \% \mathrm{CI}=1.33,14.32)]$. The finding is similar to that of Dubti town, Afar regional state, northeast Ethiopia, ${ }^{22}$ Offa district, Southern Ethiopia ${ }^{21}$ and that of Hossana, Southern Ethiopia, ${ }^{20}$ which reported early initiation of breastfeeding within 1 hour as a strong predictor of EBF.

\section{Limitation}

Finally, as a limitation. since we have used the dietary recall since birth method, we might have introduced recall bias, as the mothers might not have recalled accurately when they 
Table 3 Bivariate and Multivariate Analysis of Factors Associated with Exclusive Breast-Feeding, Harar Town, Harari Regional State, Eastern Ethiopia $(n=577)$

\begin{tabular}{|c|c|c|c|c|}
\hline \multirow[t]{2}{*}{ Variables } & \multicolumn{2}{|c|}{ Exclusive Breast-feeding } & \multicolumn{2}{|c|}{ Odds Ratio (95\% Confidence Interval) } \\
\hline & Yes & No & COR(95\% Cl) & $\operatorname{AOR}(95 \% \mathrm{Cl})$ \\
\hline \multicolumn{5}{|l|}{ Age } \\
\hline $18-25$ & 130 & 126 & I & 1 \\
\hline $26-40$ & 134 & 187 & $\mathrm{I} .44(1.04,2.01)$ & $1.98(1.10,3.57)^{*}$ \\
\hline \multicolumn{5}{|l|}{ Maternal education } \\
\hline Unable to read and write & 35 & 56 & I & I \\
\hline Primary school & 120 & 114 & $0.59(0.36,0.97)$ & $0.67(0.28,1.6 I)$ \\
\hline Secondary school and above & 89 & 116 & $0.82(0.49,1.35)$ & $0.54(0.27,1.12)$ \\
\hline College/university & 20 & 27 & $0.84(0.4 \mathrm{I}, \mathrm{I} .73)$ & $0.64(0.30,1.35)$ \\
\hline \multicolumn{5}{|l|}{ Average monthly income } \\
\hline$<2500$ & 60 & 76 & 1 & I \\
\hline $250 I-5000$ & 99 & 137 & $1.09(0.71,1.67)$ & $0.80(0.4 I, I .60)$ \\
\hline$>5000$ & 105 & 100 & $0.75(0.49,1.16)$ & $0.74(0.37,1.47)$ \\
\hline \multicolumn{5}{|l|}{ Number of pregnancies } \\
\hline $\mathrm{I}-2$ & 135 & 140 & 1 & I \\
\hline $3-4$ & 80 & 105 & $1.45(0.88,2.38)$ & $\mathrm{I} .0 \mathrm{I}(0.55, \mathrm{I} .84)$ \\
\hline 5 and above & 49 & 68 & $\mathrm{I} .8 \mathrm{I}(\mathrm{I} .0 \mathrm{I}, 3.24)$ & $I .2 I(0.59,2.5 I)$ \\
\hline \multicolumn{5}{|l|}{ Breast-feeding information } \\
\hline Yes & 215 & 49 & $1.61(1.08,2.40)$ & $1.95(1.13,3.37)^{*}$ \\
\hline No & 229 & 84 & 1 & 1 \\
\hline \multicolumn{5}{|l|}{ Antenatal care follow-up } \\
\hline Yes & 249 & 15 & $1.01(0.50,2.05)$ & $1.00(0.42,2.36)$ \\
\hline No & 295 & 18 & 1 & 1 \\
\hline \multicolumn{5}{|c|}{ Early initiation of breast-feeding } \\
\hline Yes & 252 & 311 & $7.40(1.64,13.39)$ & $12.34(1.33,14.32)^{*}$ \\
\hline No & 12 & 2 & 1 & 1 \\
\hline \multicolumn{5}{|l|}{ Knowledge about EBF } \\
\hline Good knowledge & 186 & 209 & $1.19(0.83,1.69)$ & I.16(0.72, I.87) \\
\hline Poor knowledge & 78 & 104 & I & I \\
\hline
\end{tabular}

Notes: *Significantly associated with $\mathrm{p}$-value $<0.05$ in multivariate analysis.

Abbreviations: $\mathrm{COR}$, crud odds ratio; $\mathrm{Cl}$, confidence interval; $\mathrm{AOR}$, adjusted odds ratio; $\mathrm{EBF}$, exclusive breast-feeding.

introduced a food item. This may under- or over-estimate the true prevalence of EBF. It is also difficult to establish a temporal relationship as the study design was cross-sectional.

\section{Conclusion}

The overall exclusive breast-feeding practice among the women was found to be less. Age, information on breastfeeding, and early initiation of breast feeding were found as important predictors of exclusive breast-feeding.
Improving access to information on recommended infant feeding is vital and encouraging exclusive breast-feeding among mothers through proper counseling and motherfriendly work environment is advisable.

\section{Data Sharing Statement}

All related data has been presented within the manuscript. The dataset supporting the conclusions of this article is available from the authors on reasonable request. 


\section{Acknowledgment}

The authors would like to thank the institutional review board of Saint Paulos Hospital Millennium Medical College and Ethio-Canada Maternal and Child Health Project for support of funding the study and technical collaboration. We would like to thank Harari Health Bureau for their support and collaboration. We also thank the data collectors and participants of the study.

\section{Author Contributions}

All authors made substantial contributions to conception and design, acquisition of data, or analysis and interpretation of data; took part in drafting the article or revising it critically for important intellectual content; gave final approval of the version to be published; and agree to be accountable for all aspects of the work.

\section{Disclosure}

The authors declare no conflicts of interest in this work.

\section{References}

1. WHO, UNICEF. Indicators for Assessing Infant and Young Child Feeding Practices Country Profiles. Geneva, Switzerland: WHO press, world health organization; 2010. Available from: http://whqlib doc.who.int/publications/2010/.

2. World Health Organization. e-Library of Evidence for Nutrition Actions (eLENA). Available from: http://www.who.int/elena/titles/ exclusive_breastfeeding/en/. 2015.

3. WHO/UNICEF. Baby-Friendly Hospital Initiative: Revised, Updated and Expanded for Integrated Care. Geneva: World Health Organization; 2009. Available from:: http://www.who.int/nutrition/ topics/bfhi/en/index.html.

4. UNICEF. Committing to Child Survival: A Promise Renewed Progress Report. New York; 2014.

5. Dachew BA, Bifftu BB. Breastfeeding practice and associated factors among female nurses and midwives at North Gondar Zone, Northwest Ethiopia: a cross-sectional institution based study. Int Breastfeed J. 2014;9(1):11. doi:10.1186/1746-4358-9-11

6. UNICEF. Improving Exclusive Breastfeeding Practices by Using Communication for Development in Infant and Young Child Feeding Programmes; 2010.

7. Central Statistical Agency (CSA) [Ethiopia], ICF. Ethiopia Demographic and Health Survey 2016: Key Indicators Report. Addis Ababa, Ethiopia, and Rockville, Maryland, USA: CSA and ICF; 2016.

8. Ethiopian Federal Ministry of Health, UNICEF. Forces to Promote Safe Breastfeeding. Addis Ababa; 2014

9. CSA. Ethiopian Housing and Population Census Report in Population and Housing Census. Addis Ababa: Central Statistics Authority; 2007.

10. Assefa N, Semahegn A. Fertility is below replacement in harar health and demographic surveillance system (harar HDSS), Harar town, Eastern Ethiopia. Fertili Res Pract. 2016;2(10). doi:10.1186/ s40738-016-0023-8

11. Tambe BA, Mimboe CSB, Nchung JA, et al. The determinants of exclusive breastfeeding in Cameroon, Sub-Saharan Africa. Trends Gen Pract. 2018;1(3):1-6. doi:10.15761/TGP.1000113
12. Bhandari MS, Manandhar P, Tamrakar D. Practice of breastfeeding and its barriers among women working in tertiary level hospitals. J Nepal Med Assoc. 2019;57(215):8-13.

13. Tesfa Getanew W, Addisu Workineh K, Melkie E. Assessment of exclusive breast feeding practice and associated factors in Mecha District, North West Ethiopia. Sci J Public Health. 2014;2 (4):330-336. doi:10.11648/j.sjph.20140204.24

14. Seid AM, Yesuf ME, Koye DN. Prevalence of exclusive breastfeeding practices and associated factors among mothers in Bahir Dar city, Northwest Ethiopia: a community based cross-sectional study. Int Breastfeed J. 2013;8(1):14. doi:10.1186/1746-4358-8-14

15. Sefene A, Birhanu D, Awoke W, et al. Determinants of exclusive breastfeeding practice among mothers of children age less than 6 month in bahir Dar City administration, Northwest Ethiopia; a community based cross-sectional survey. Sci J Clin Med. 2013;2 (6):153-159. doi:10.11648/j.sjcm.20130206.12

16. Tewabe T, Mandesh A, Gualu T, et al. Exclusive breastfeeding practice and associated factors among mothers in Motta town, East Gojjam zone, Amhara Regional State, Ethiopia, 2015: a cross-sectional study. Int Breastfeed J. 2017;12(1):12. doi:10.1186/ s13006-017-0103-3

17. Asfaw MM, Argaw MD, Kefene ZK. Factors associated with exclusive breastfeeding practices in Debre Berhan District, Central Ethiopia: a cross-sectional community-based study. Int Breastfeed J. 2015;10(1):23. doi:10.1186/s13006-015-0049-2

18. Mekuria G, Edris M. Exclusive breastfeeding and associated factors among mothers in Debre Markos, Northwest Ethiopia: a cross-sectional study. Int Breastfeed J. 2015;10(1):1. doi:10.1186/ s13006-014-0027-0

19. Sonko A, Worku A. Prevalence and predictors of exclusive breastfeeding for the first six months of life among women in Halaba special woreda, Southern Nations, Nationalities and Peoples' Region/SNNPR/, Ethiopia: a community based cross-sectional study. Arch Public Health. 2015;73(1):53. doi:10.1186/s13690-0150098-4

20. Earsido A, Abebe W, Dereje N. Prevalence and determinants of exclusive breastfeeding practices among infants in Hossana Town, Southern Ethiopia: a community based cross-sectional study. EC Gynaecol. 2017;4(3):69-79.

21. Lenja A, Demissie T, Yohannes B, et al. Determinants of exclusive breastfeeding practice to infants aged less than six months in Offa district, Southern Ethiopia: a cross-sectional study. Int Breastfeed J. 2016;11(1):32. doi:10.1186/s13006-016-0091-8

22. Liben ML, Gemechu YB, Adugnew M, et al. Factors associated with exclusive breastfeeding practices among mothers in Dubti town, afar regional state, northeast Ethiopia: a community based cross-sectional study. Int Breastfeed J. 2016;11(1):4. doi:10.1186/s13006-016-0064-y

23. Oche MO, Umar AS, Ahmed H. Knowledge and practice of exclusive breastfeeding in Kware, Nigeria. Afr Health Sci. 2011;11 (3):518-523

24. Biks GA, Tariku A, Assefa G. Effects of antenatal care and institutional delivery on exclusive breastfeeding practice in northwest Ethiopia: a nested case-control study. Int Breastfeed J. 2015;10(30). doi:10.1186/s13006-015-0055-4

25. Shifraw T, Worku A, Berhane Y. Factors associated with exclusive breastfeeding practices of urban women in Addis Ababa public health centers, Ethiopia: a cross-sectional study. Int Breastfeed J. 2015;10 (22). doi:10.1186/s13006-015-0047-4

26. Maonga AR, Mahande MJ, Damian DJ, et al. Factors affecting exclusive breastfeeding among women in muheza district tanga northeastern tanzania: a mixed-method community based study. Matern Child Health J. 2016;20(1):77-87. doi:10.1007/s10995-015-1805-z

27. Hossain M, Islam A, Kamarul T, et al. Exclusive breastfeeding practice during the first six months of an infant's life in Bangladesh: a country based cross-sectional study. BMC Pediatr. 2018;18(93). doi:10.1186/s12887-018-1076-0. 
28. Alamirew MW, Bayu NH, Tebeje NB, et al. Knowledge and Attitude Towards Exclusive Breast Feeding Among Mothers Attending Antenatal and Immunization Clinic at Dabat Health Center, Northwest Ethiopia: A Cross-Sectional Institution Based Study. Vol. 2017. Hindawi, Nursing Research and Practice; 2017. Article ID 6561028.

29. Demilew YM. Factors associated with mothers' knowledge on infant and young child feeding recommendation in slum areas of Bahir Dar City, Ethiopia: a cross-sectional study. ?BMC Res Notes. 2017;10 (1):191. doi:10.1186/s13104-017-2510-3
30. Tadele N, Habta F, Akmel D, et al. Knowledge, attitude and practice towards exclusive breastfeeding among lactating mothers in Mizan Aman town, Southwestern Ethiopia: a descriptive cross-sectional study. Int Breastfeed J. 2016;11(3). doi:10.1186/s13006-016-0062-0.

\section{Publish your work in this journal}

Pediatric Health, Medicine and Therapeutics is an international, peerreviewed, open access journal publishing original research, reports, editorials, reviews and commentaries. All aspects of health maintenance, preventative measures and disease treatment interventions are addressed within the journal. Practitioners from all disciplines are invited to submit their work as well as healthcare researchers and patient support groups. The manuscript management system is completely online and includes a very quick and fair peer-review system. Visit http://www.dovepress.com/testimonials.php to read real quotes from published authors.

Submit your manuscript here: http://www.dovepress.com/pediatric-health-medicine-and-therapeutics-journal 